Article

\title{
Improvement of Electrical Performance in P-Channel LTPS Thin-Film Transistor with a-Si:H Surface Passivation
}

\author{
Kyungsoo Jang, Youngkuk Kim, Pham Duy Phong, Younjung Lee, Joonghyun Park* *ib and \\ Junsin $\mathrm{Yi}^{*}$ \\ College of Information and Communication Engineering, Sungkyunkwan University, 2066 Seobu-ro, Jangan-gu, \\ Suwon-si, Gyeonggi-do 16419, Korea; jks30716@skku.edu (K.J.); bri3tain@skku.edu (Y.K.); \\ pdphong@skku.edu (P.D.P.); younjlee@paran.com (Y.L.) \\ * Correspondence: jhyun21.park@gmail.com (J.P.); junsin@skku.edu (J.Y.); \\ Tel.: +82-31-290-7139 (J.P.); +82-31-290-7139 (J.Y.)
}

Received: 1 November 2018; Accepted: 28 December 2018; Published: 7 January 2019

check for updates

\begin{abstract}
We report the effects of surface passivation by depositing a hydrogenated amorphous silicon (a-Si:H) layer on the electrical characteristics of low temperature polycrystalline silicon thin film transistors (LTPS TFTs). The intrinsic a-Si:H layer was optimized by hydrogen dilution and its structural and electrical characteristics were investigated. The a-Si:H layer in the transition region between a-Si:H and $\mu \mathrm{c}-\mathrm{Si}: \mathrm{H}$ resulted in superior device characteristics. Using a-Si:H passivation layer, the field-effect mobility of the LTPS TFT was increased by 78.4\% compared with conventional LTPS TFT. Moreover, the leakage current measured at $\mathrm{V}_{\mathrm{GS}}$ of $5 \mathrm{~V}$ was suppressed because the defect sites at the poly-Si grain boundaries were well passivated. Our passivation layer, which allows thorough control of the crystallinity and passivation-quality, should be considered as a candidate for high performance LTPS TFTs.
\end{abstract}

Keywords: poly-Si TFT; LTPS TFT; FT-IR; Raman; surface passivation; leakage current

\section{Introduction}

Currently, the display industry has been widely investigating to meet new market demands for low-cost, large-size, high-resolution, high-frame-rate, and 3D displays. Thin film transistors (TFTs) as switching or driving devices are one of the most important components. Low temperature polycrystalline silicon (LTPS) TFTs have been widely used because their field effect mobility is higher than that of hydrogenated amorphous silicon (a-Si:H) TFTs, so that high resolution displays with ultra-high densities $(3840 \times 2160$, UHD) can be fabricated. Because poly-Si TFTs are very robust under electrical and optical stress, they can be used in various applications [1]. However, there are crucial disadvantages of LTPS TFTs, such as high off-state leakage currents originating from defects in the grain boundaries of poly-Si [2]. To reduce leakage currents in poly-Si TFTs, some additional structures have been proposed including lightly doped drain (LDD) and offset gate structures [3]. However, these structures require additional processing and costs, so they have not been fully applied in the display industry. To reduce the off-state leakage current, Kim et al. proposed a simple method based on the insertion of a thin $(10 \mathrm{~nm})$ a-Si:H layer [4]. They explained the reason for the reduced leakage current using an energy band diagram and the current paths in the LTPS TFT with an a-Si:H passivation layer and a larger band gap. Inserting a larger band gap material between the active layer and gate insulator can result in a reduced rate of thermionic emission. Thus, the minimum leakage current was successfully reduced and the on/off ratio was improved. However, the field-effect mobility $\left(12 \mathrm{~cm}^{2} / \mathrm{V} \cdot \mathrm{s}\right)$ of the LTPS TFT with an a-Si:H passivation layer was remarkably lower than that of a TFT 
without an a-Si:H passivation layer $\left(58.3 \mathrm{~cm}^{2} / \mathrm{V} \cdot \mathrm{s}\right)$. Although they solved the leakage current problem in LTPS TFTs through the simple insertion of a passivation layer with a larger band gap, the field-effect mobility was severely decreased, so that the high performance of poly-Si TFTs disappeared.

In this work, we investigated the reduction of leakage current without sacrificing the field-effect mobility. We deposited an a-Si:H passivation layer on the poly-Si layer. An a-Si:H passivation layer has been used to achieve a high conversion efficiency in hetero junction solar cells $[5,6]$. However, the use of an a-Si:H passivation layer in poly-Si TFTs has so far not been reported. The optimized a-Si:H layer passivates dangling bonds at the interface and reduces carrier recombination, thus improving the device characteristics. We investigated the deposition of an a-Si:H passivation layer and optimized the dilution gas ratio. Different a-Si:H layers were deposited using different gas ratios of $\mathrm{SiH}_{4}: \mathrm{H}_{2}$, and the characteristics of the a-Si:H layers were evaluated by Raman spectroscopy, Fourier transform infrared spectroscopy (FT-IR), and quasi-steady-state photoconductance (QSSPC) measurements to examine their crystallinity $\left(\mathrm{X}_{\mathrm{C}}\right)$, defects, bonding, and passivation-quality. Finally, LTPS TFTs with different passivation layers were fabricated and their electrical performance was evaluated. The leakage current was successfully reduced without sacrificing the field-effect mobility by using an optimized a-Si:H layer.

\section{Device Fabrication}

A 50-nm-thick a-Si:H film was deposited on the 300-nm-thick buffer oxide layer by plasma enhanced chemical vapor deposition (PECVD). The a-Si:H layer was dehydrogenated at $400{ }^{\circ} \mathrm{C}$ in a $\mathrm{N}_{2}$ atmosphere for $10 \mathrm{~min}$ and then crystallized using an $\mathrm{XeCl}(308 \mathrm{~nm})$ excimer laser. After the formation of poly-Si, the intrinsic a-Si:H passivation layer was deposited on the poly-Si. To investigate the effect of surface passivation on the electrical performance of LTPS TFTs, the 10-nm-thick passivation layers were deposited by PECVD using different silane $\left(\mathrm{SiH}_{4}\right)$ and hydrogen $\left(\mathrm{H}_{2}\right)$ gas flow rates. Various dilution gases, such as helium (He) and hydrogen, have already been studied for the deposition of a-Si:H [7]. The layer of a-Si:H deposited using $\mathrm{He}$ as a dilution gas was found to contain disordered and loose networks. However, the a-Si:H deposited with $\mathrm{H}_{2}$ dilution gas was found to form denser structure, so we used $\mathrm{H}_{2}$ as the dilution gas in this work. The $\mathrm{SiH}_{4}$ flow rate was varied from 20 to $6 \mathrm{sccm}$ and the $\mathrm{H}_{2}$ flow rate was varied from 20 to $36 \mathrm{sccm}$. The gas ratio (GR) of $\mathrm{H}_{2} /\left(\mathrm{SiH}_{4}+\mathrm{H}_{2}\right)$ was changed from 0.50 to 0.86 , while the plasma power density was fixed at $1.27 \mathrm{~W} / \mathrm{cm}^{2}$. The deposition temperature for the passivation layers was $180{ }^{\circ} \mathrm{C}$, and the $\mathrm{RF}$ power was $100 \mathrm{~W}$, while the deposition pressure was 50 mTorr. The highest and lowest deposition rates of a-Si:H passivation layers were $2.59 \mathrm{~nm} / \mathrm{min}$ at GR of 0.75 and $0.55 \mathrm{~nm} / \mathrm{min}$ at GR of 0.5 , respectively. The 220-nm-thick $\mathrm{SiO}_{2}$ gate insulator was deposited by PECVD at $180{ }^{\circ} \mathrm{C}$ on the passivation layer. An aluminium layer was deposited on the gate insulator to serve as the gate metal, and then the substrate was patterned. Source and drain doping were performed using a boron ion shower for the p-type TFT. Then, the source and drain regions were activated at $400{ }^{\circ} \mathrm{C}$ in a $\mathrm{N}_{2}$ atmosphere for $4 \mathrm{~h}$. The channel width and length of the fabricated TFTs were 180 and $50 \mu \mathrm{m}$, respectively. The electrical characteristics of the LTPS TFTs with different passivation layers were examined using a semiconductor parameter analyzer at room temperature under dark conditions. To further understand the passivation layer's structural and electrical characteristics, Raman spectroscopy, Fourier transform infrared spectroscopy (FT-IR), and quasi-steady-state photoconductivity (QSSPC) measurements were conducted.

\section{Results and Discussion}

Raman spectroscopy is a well-known technique for distinguishing the structural characteristics of thin films. In particular, it can indicate the ordering of an amorphous silicon film. The defects of a-Si:H are mainly detected at low frequency $\left(300 \sim 400 \mathrm{~cm}^{-1}\right)$. We investigated the use of Raman spectroscopy for evaluating the passivation layer. Figure 1a shows the Raman spectroscopy of passivation layers deposited using different GR values. The 100-nm-thick passivation layer was deposited on a glass substrate. The measured Raman spectroscopy were decomposed into several 
gaussian component peaks located at around 150, 300, 410, and $480 \mathrm{~cm}^{-1}$, corresponding to the transverse acoustic (TA), longitudinal acoustic (LA), longitudinal optical (LO), and transverse optical (TO) modes [8-10]. The Raman characteristics of the passivation layers were strongly influenced by the GR. When the GR was increased from 0.5 to 0.75 , the ratios of TA/TO, LA/TO, and LO/TO were reduced. When the GR was over 0.75 , the ratios of TA/TO, LA/TO, and LO/TO rapidly increased. The increase of TA/TO, LA/TO, and $\mathrm{LO} / \mathrm{TO}$ has been related to the enhanced generation of defects in passivation layers [8-10]. Figure $1 \mathrm{~b}$ shows the ratios of TA/TO, LA/TO, and LO/TO at different GR values. Furthermore, the crystallinity $\left(\mathrm{X}_{\mathrm{C}}\right)$ of the passivation layer was calculated using the Raman peak ratio of the broad band at $480 \mathrm{~cm}^{-1}$ (a-Si:H) and the strong band at $520 \mathrm{~cm}^{-1}$ (c-Si). A Raman spectrum characteristic of $\mu \mathrm{c}-\mathrm{Si}: \mathrm{H}$ was observed at GR values above 0.75 and the $\mathrm{X}_{\mathrm{C}}$ sharply increased.

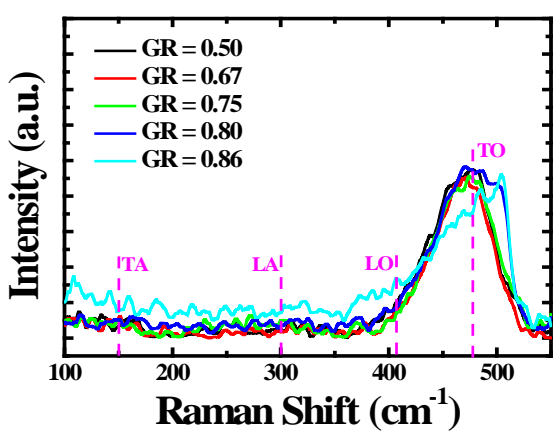

(a)

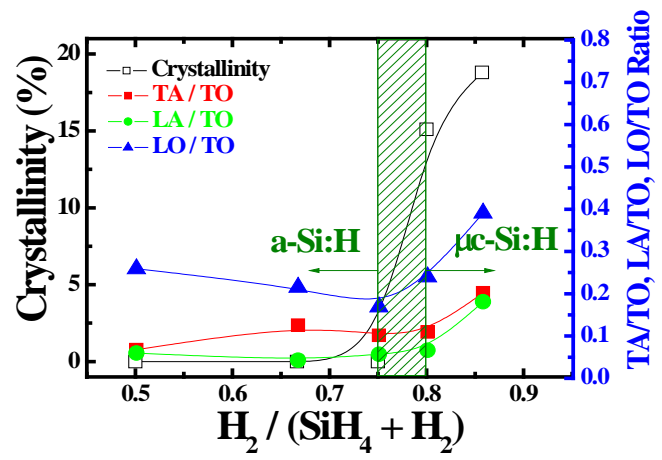

(b)

Figure 1. (a) The Raman spectroscopy of passivation layers as a function of gas ratio (GR) (b) The dependence of the Raman characteristic parameters and crystallinity on GR.

To further understand the silicon hydrogen bonds, we performed FT-IR measurements, which can easily detect the incorporation of $\mathrm{Si}$ and $\mathrm{H}$. To analyze the FT-IR, a 100-nm-thick passivation layer was deposited on c-Si. Figure $2 \mathrm{a}, \mathrm{b}$ shows the microstructure parameter $\left(\mathrm{R}^{*}\right)$ of the passivation layers deposited by different GR values. The FT-IR absorption of a-Si:H and $\mu \mathrm{c}-\mathrm{Si}: \mathrm{H}$ provides specific information about the type of bonds present between Si and H [11,12]. In this study, two kinds of bonds with a stretching vibrational mode were observed to investigate the structural properties of the passivation layers, such as $\mathrm{Si}-\mathrm{H}$ bonds with a peak at around $2000 \mathrm{~cm}^{-1}$ and $\mathrm{Si}=\mathrm{H}_{2}$ bonds with a peak at around $2090 \mathrm{~cm}^{-1}$. As the GR was increased to $0.75, \mathrm{I}_{2000}$ also increased. However, $\mathrm{I}_{2000}$ decreased for GR values over 0.8 . To calculate the properties of the passivation layer, the quantity, $R^{*}$, was introduced. $\mathrm{R}^{*}$ was defined as $\mathrm{I}_{2000} /\left(\mathrm{I}_{2000}+\mathrm{I}_{2090}\right)$. The $\mathrm{Si}=\mathrm{H}_{2}$ bonding factor representing the quality of the layer was regarded as a measure of the defects or voids. $\mathrm{As} \mathrm{Si}=\mathrm{H}_{2}$ bonding increased, many defects remained in the thin film. The $R^{*}$ value gradually increased from 0.27 at a GR of 0.5 to 0.45 at a GR of 0.75 and sharply decreased to 0.15 at a GR of 0.86 . Based on the correlation with Raman results, the highest $\mathrm{R}^{*}$ value and the transition region from a-Si:H to $\mu c-\mathrm{Si}: \mathrm{H}$ were well matched.

To investigate the characteristics of different passivation layers, QSSPC measurements were conducted for a-Si:H on a single crystalline silicon wafer (c-Si) (a-Si:H/c-Si), $\mu c-S i: H$ on c-Si $(\mu \mathrm{c}-\mathrm{Si} \mathrm{H} / \mathrm{c}-\mathrm{Si})$, and a pure c-Si sample. Figure $2 \mathrm{c}$ shows the carrier lifetime characteristics of the passivation layers formed using different passivation layers. This measurement is widely used in the contactless characterization of solar cells. Many thin films, such as a-Si:H and $\mathrm{Al}_{2} \mathrm{O}_{3}$, have been employed to passivate the interface or bulk defects $[13,14]$. The system is based on a radio frequency bridge with an inductive coil that generates electromagnetic fields in the wafer. The interfaces of a silicon substrate represent a severe discontinuity in its crystalline structure. The poly-Si, especially at the interface, has many dangling bonds, so that a large density of defect levels could be found within the bandgap near the interface. By using an appropriate surface passivation layer, such as an optimized a-Si:H film, these dangling bonds in poly-Si grain boundaries could be passivated, thus reducing the interface trap density [15]. A flash lamp was irradiated on a semiconductor surface. The excessive 
electron and hole pairs were generated, and then generated carriers were decayed. The minority carrier lifetime $(\tau)$ is the amount of time during which photo-generated carriers remain free, highly mobile in the material, and at the surface, before recombining in some defect sites [16]. Because the $\tau$ of a thin film could be dominantly influenced by surface conditioning, and it can be useful for evaluating the passivation quality. In this study, c-Si substrate without a passivation layer was used as a reference with $\tau$ value of $22.23 \mu \mathrm{s}$. The $\tau$ of a-Si:H/c-Si with GR of 0.75 was the highest at $51.77 \mu$ s and the $\tau$ of $\mu \mathrm{c}-\mathrm{Si}: \mathrm{H} / \mathrm{c}-\mathrm{Si}$ with GR over 0.75 was reduced below the reference $\tau$. By using the optimized a-Si:H $(G R=0.75)$ passivation layer, the lowest interface trapped charge density was expected.
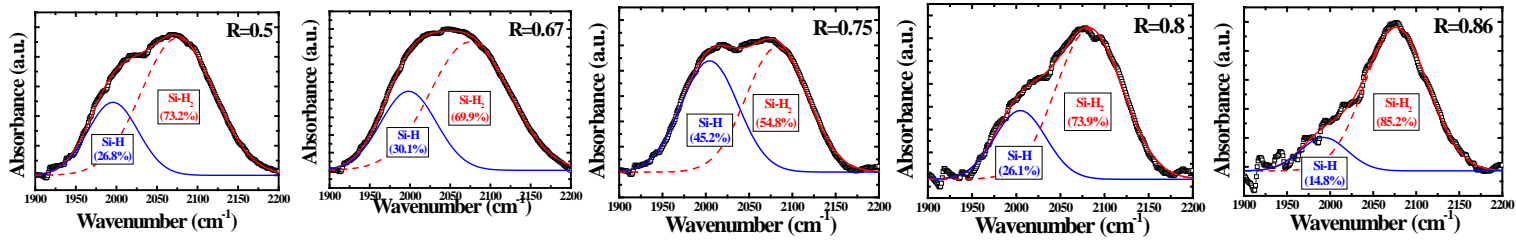

(a)

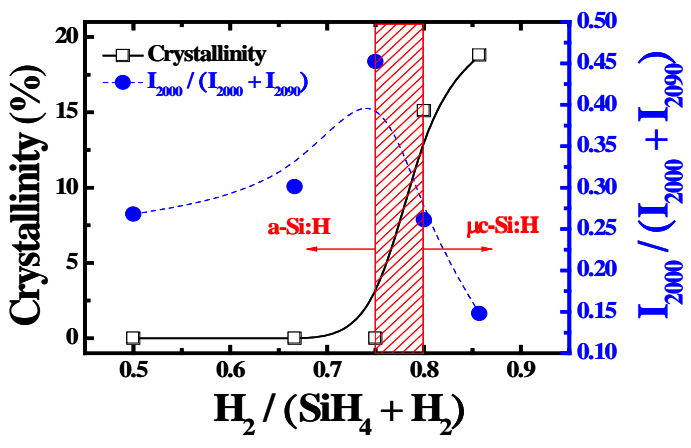

(b)

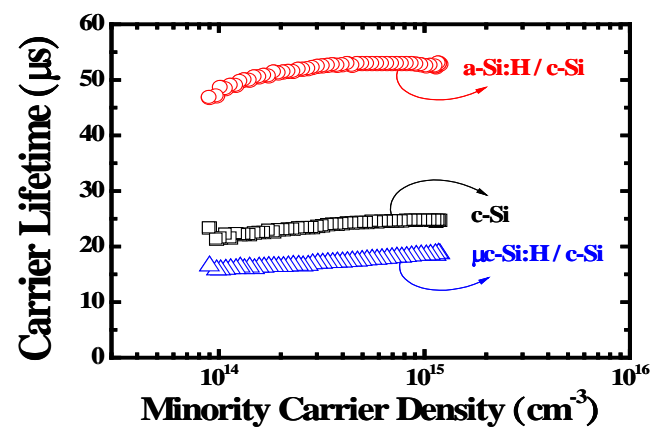

(c)

Figure 2. (a) The Fourier transform infrared (FT-IR) spectroscopy characteristics as a function of GR (b) The calculated crystallinity by Raman spectroscopy and microstructure by FT-IR (c) Carrier lifetime characteristics of the passivation layers formed using different passivation layers by QSSPC.

Figure 3 shows the electrical properties obtained from transfer curves of the p-channel LTPS TFTs with and without passivation layers on the poly-Si layer. The width and length of the p-channel LTPS TFTs were $180 \mu \mathrm{m}$ and $50 \mu \mathrm{m}$, respectively (Width/Length $=3.6$ ). The transfer curves were measured at a drain bias of $-0.1 \mathrm{~V}$. The extracted electrical properties of the LTPS TFTs with and without passivation layers are displayed in Table 1 . The field effect mobility $(\mu)$ was calculated by the maximum transconductance method at $\mathrm{V}_{\mathrm{DS}}=-0.1 \mathrm{~V}$ and the threshold voltage was observed at the (Width/Length) $\times \mathrm{V}_{\mathrm{GS}}$ at drain current density of $10 \mathrm{nA}$. The leakage current $\left(I_{D \text {.Leak }}\right)$ was measured at a $V_{\mathrm{GS}}$ of $5 \mathrm{~V}$. The LTPS TFT without a passivation layer had the following electrical properties: $\mu$ of $49.58 \mathrm{~cm}^{2} / \mathrm{V} \cdot \mathrm{s}$, subthreshold swing (S.S.) of $0.91 \mathrm{~V} / \mathrm{dec}$, and the $I_{D \text {.Leak }}$ of $7.62 \times 10^{-11} \mathrm{~A} / \mathrm{cm}^{2}$. However, when the optimized passivation layer $(\mathrm{GR}=0.75)$ was employed on poly-Si layer, the LTPS TFT exhibited high $\mu$ of $88.53 \mathrm{~cm}^{2} / \mathrm{V} \cdot \mathrm{s}$, S.S of $0.58 \mathrm{~V} / \mathrm{dec}$ and $I_{D . \text { Leak }}$ of $2.46 \times 10^{-12} \mathrm{~A} / \mathrm{cm}^{2}$. Moreover, the threshold voltage was considerably increased. These improved TFT characteristics were attributed to the fact that the optimized a-Si:H layer can easily passivate the poly-Si interface with high trap densities. Especially, it was known that the improved threshold voltage $\left(V_{T H}\right)$ and S.S. are related to deep defect states. The characteristics of poly-Si TFTs fabricated at a low temperature were dominated by interface and grain boundary defect states. It was clear that the amount of trap states between the poly-Si layer and the gate oxide layer was reduced due to the optimized a-Si:H layer, as proven by FT-IR and QSSPC measurements. The leakage current was also reduced by the passivation layer. Significant band-bending occurs between the channel and drain region because of the reversely biased p-n junction, where the leakage current can flow via the defect sites at the poly-Si grain boundary [17]. 
The optimized passivation layer was effective to reduce the number of such defect sites. To express this numerically, the interface defect sites between $\mathrm{SiO}_{2}$ and poly-Si were estimated by the Levinson and Proano method [18,19]. The number of defect sites can be expressed as:

$$
\left.N_{T}=\left[\left(\frac{S . S .}{\ln 10}\right)\left(\frac{q}{k T}\right)-1\right)\right]\left(\frac{C_{o x}}{q}\right)
$$

where S.S. is the subthreshold swing, $q$ is the unit charge, $T$ is the absolute temperature, $k$ is the boltzmann constant and $C_{o x}$ is the capacitance of the gate oxide.

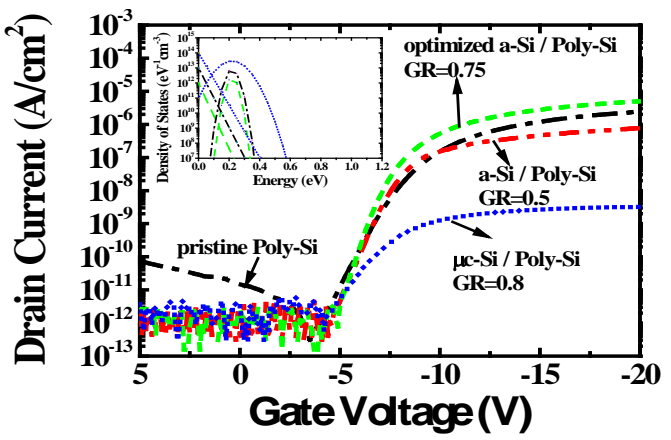

Figure 3. Transfer characteristics of low temperature poly-Si thin film transistors (LTPS TFTs) with and without passivation layers. The inset figure shows the defect states in the LTPS TFTs simulated by technology computer-aided design (TCAD).

Table 1. Comparison of electrical characteristics of p-channel LTPS TFTs with and without passivation layers on glass substrates.

\begin{tabular}{ccccc}
\hline & Without Passivation Layer & \multicolumn{3}{c}{ With Passivation Layer } \\
\cline { 2 - 5 } Parameter & Poly-Si & $\begin{array}{c}\text { a-Si:H } \\
(\mathbf{G R}=\mathbf{0 . 5})\end{array}$ & $\begin{array}{c}\text { Opt. a-Si:H } \\
\mathbf{( G R}=\mathbf{0 . 7 5})\end{array}$ & $\begin{array}{c}\boldsymbol{\mu c}-\mathbf{S i}: \mathbf{H} \\
(\mathbf{G R}=\mathbf{0 . 8})\end{array}$ \\
\hline$\mu\left(\mathrm{cm}^{2} / \mathrm{Vs}\right)$ & 49.58 & 18.2 & 88.53 & 1.3 \\
S.S. $(\mathrm{V} / \mathrm{dec})$ & 0.91 & 0.72 & 0.58 & 1.19 \\
$N_{T}\left(\mathrm{~cm}^{-2}\right)$ & $7.38 \times 10^{12}$ & $5.78 \times 10^{12}$ & $4.62 \times 10^{12}$ & $9.71 \times 10^{12}$ \\
$V_{T H}(\mathrm{~V})$ & -6.75 & -6 & -5.9 & -6.4 \\
$I_{\text {d.leak }}\left(\mathrm{A} / \mathrm{cm}^{2}\right)$ & $7.62 \times 10^{-11}$ & $2.3 \times 10^{-12}$ & $2.46 \times 10^{-12}$ & $3.68 \times 10^{-12}$ \\
\hline
\end{tabular}

The technology computer aided design (TCAD) simulation was conducted to understand the defect states distribution in the LTPS TFT. The characteristics of LTPS TFT can be modeled by the distribution of the density of states (DOS) in the band gap. In the case of p-type LTPS TFT, the on current and field effect mobility was affected by the density of the donor like tail state defects (NTD) near the valance band, while the threshold swing and threshold voltage was affected by the donor like deep state defects (NGD). The transfer characteristics of LTPS TFT was fitted in TCAD simulation. The LTPS TFT without a passivation layer had NTD of $9.9 \times 10^{12} / \mathrm{eVcm}^{3}$ and NGD of $7.7 \times 10^{12} / \mathrm{eVcm}^{3}$. The LTPS TFT with the optimized a-Si:H passivation layer had NTD of $9.9 \times 10^{11} / \mathrm{eVcm}^{3}$ and NGD of $2.3 \times 10^{12} / \mathrm{eVcm}^{3}$. Additionally, the LTPS TFT with the $\mu \mathrm{c}-\mathrm{Si}: \mathrm{H}$ passivation layer had NTD of $9.9 \times 10^{13} / \mathrm{eVcm}^{3}$ and NGD of $2.9 \times 10^{13} / \mathrm{eVcm}^{3}$.

The number of interface defect states was successfully reduced by using a passivation layer. However, the on current $\left(\mathrm{V}_{\mathrm{GS}}<-10 \mathrm{~V}\right)$ characteristics were quite different. In the case of LTPS TFTs with $\mu c-S i: H$ passivation layers, the electrical properties were degraded with higher S.S and lower field-effect mobility. The most likely reason for this degradation is the creation of new dangling bonds on the poly-Si layer by highly diluted hydrogen. Our passivation process can supply additional hydrogen for the passivation, but it could also create new dangling bonds [20]. Therefore, the dilution gas ratio for the passivation layer was carefully controlled to avoid creating new dangling bonds. 
In the LTPS TFT, various defect states in the grain boundaries and intra-grain influence the electrical characteristics as well as the carrier transport from the source to the drain. The poly-Si is often terminated at the interface imperfectly. The trap states at the grain boundaries are associated with the lattice discontinuities by differently oriented grains. The a-Si:H passivation layer supplies hydrogen atoms combined with silicon, and it can passivate dangling bonds in poly-Si. When the passivation layer was deposited at low values of GR, the hydrogen is predominantly incorporated in the mono-hydrogen $(\mathrm{Si}-\mathrm{H})$ bonding. However, as $\mathrm{GR}$ is increased, the bonding shifts from mono-hydrogen $(\mathrm{Si}-\mathrm{H})$ to di-hydrogen $\left(\mathrm{Si}-\mathrm{H}_{2}\right)$ [12]. We think that a proper mixture of $\mathrm{Si}-\mathrm{H}$ and $\mathrm{Si}-\mathrm{H}_{2}$ in the optimized a-Si:H layer might be a good passivation quality.

Figure 4 shows a schematic diagram of the energy bands of p-channel LTPS TFTs with and without passivation layers under negative and positive gate bias based on the energy band difference, defect density, and current paths. When a negative gate voltage was applied to the LTPS TFTs, the energy band diagram is represented in Figure 4, (a) for 'only poly-Si', (b) 'a-Si:H/poly-Si', and (c) $\mu c-S i: H / p o l y-S i$. Compared to the diagram in (a), the a-Si:H/poly-Si layers resulted in a bandgap difference between a-Si:H $\left(E_{g}=1.88 \mathrm{eV}\right)$ and poly-Si $\left(E_{g}=1.12 \mathrm{eV}\right)$, and the channel carrier mobility was enhanced due to the improved interface quality. In the case of $\mu \mathrm{c}-\mathrm{Si}: \mathrm{H}\left(\mathrm{E}_{\mathrm{g}}=1.2 \mathrm{eV}\right) /$ poly-Si, the effect of this bandgap difference was smaller, resulting in a degraded interface quality. When the gate voltage was positive, the energy band diagram can be represented as in Figure 4, (d) for 'only poly-Si', (e) 'a-Si:H/poly-Si', and (f) $\mu \mathrm{c}-\mathrm{Si}: \mathrm{H} /$ poly-Si. In the case of (d), when the gate voltage was positive, the carriers flowed from the drain to the source via poly-Si. In the case of the poly-Si with passivation layer, when the gate voltage was positive, the carriers flowed from the drain to the source via the passivation layer and/or passivation layer/poly-Si/buffer. The field emission, denoted by path $\mathrm{C}$, for the $\mathrm{SiO}_{2}$ /poly-Si TFT was suppressed by the presence of a wide band gap passivation. Therefore, the dominant current path may be A or B as depicted in Figure $4 \mathrm{~d}-\mathrm{f}$ [21]. Path A represents the thermionic field emission in the passivation region and path $B$ represents the thermionic field emission in the poly-Si due to the weakened electric field in the poly-Si by the presence of the passivation layer.
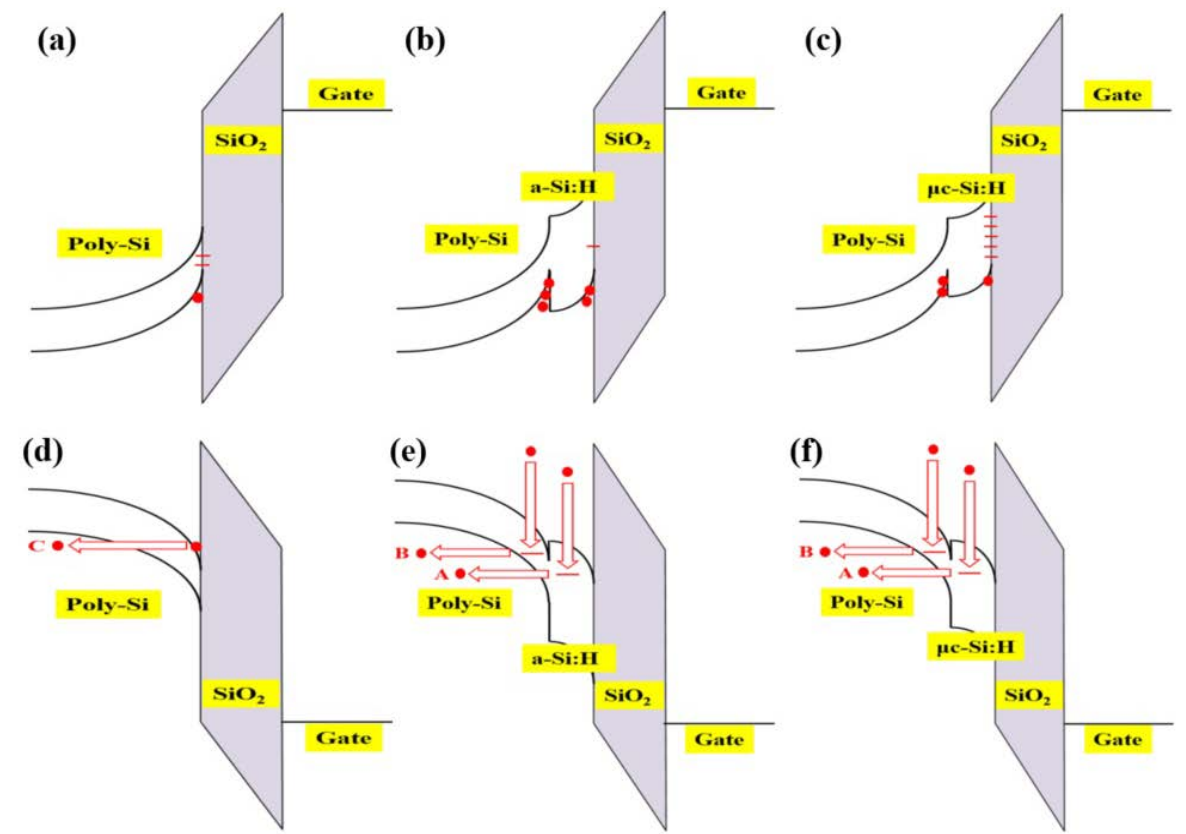

Figure 4. The schematic energy band diagram of p-channel LTPS TFTs with and without passivation layers under negative and positive gate bias based on the energy band difference, defect density, and current paths. (a) Only poly-Si under negative gate bias, (b) a-Si:H/poly-Si under negative gate bias, (c) $\mu \mathrm{c}-\mathrm{Si}: \mathrm{H} /$ poly-Si under negative gate bias, (d) only poly-Si under positive gate bias, (e) a-Si:H/poly-Si under positive gate bias, and (f) $\mu \mathrm{c}-\mathrm{Si}: \mathrm{H} /$ poly-Si under positive gate bias. 


\section{Conclusions}

We fabricated p-channel LTPS TFTs with a-Si:H passivation layer to reduce the leakage current without sacrificing field effect mobility. Poly-Si TFTs have excellent and reliable electrical characteristics, but they still suffer from leakage currents under off state bias. To suppress the leakage current, many techniques have been tried, but the field-effect mobility of the poly-Si TFT was severely decreased. In this work, a thin a-Si:H passivation layer with the wide band gap and high passivation-quality was deposited on poly-Si layer. The a-Si passivation layer was optimized by controlling the dilution gas ratio and its structural and electrical characteristics were reported. The on state and off state characteristics of the poly-Si TFTs with optimized a-Si:H passivation layer were considerably improved because the defect sites at the poly-Si grain boundaries were well passivated. Based on the findings of this study, the use of the passivation layer with high passivation-quality should be considered as potential candidates for high performance LTPS TFTs.

Author Contributions: All authors contributed to this work. Write manuscript, K.J.; Conceptualization, Y.K., Y.L.; Measurement, P.D.P.; Simulation and analysis, J.P.; Supervision, J.Y.

Funding: This research was supported by Basic Science Research Program through the National Research Foundation (NRF) of Korea funded by the Ministry of Science, ICT \& Future Planning (NRF-2017R1D1A1B03034984). This research was supported by Basic Science Research Program through the National Research Foundation (NRF) of Korea funded by the Ministry of Education (NRF-2010-0020210).

Conflicts of Interest: The authors declare no conflict of interest.

\section{References}

1. Serikawa, T.; Shirai, T.; Okamoto, T.; Suyama, S. Low temperature fabrication of high mobility poly-Si TFT's for Large-Area LCD's. IEEE Trans. Electron Devices 1989, 36, 1929-1933. [CrossRef]

2. Lih, J.; Sung, C.; Li, C.; Hsiao, T.; Lee, H. Comparison of a-Si and poly-Si for AMOLED displays. J. Soc. Inf. Disp. 2012, 12, 367-371. [CrossRef]

3. Orouji, A.A.; Jagadeshi, M. Leakage current reduction techniques in poly-Si TFTs for active matrix liquid crystal displays: A comprehensive study. IEEE Trans. Device Mater. Reliab. 2006, 6, 315-325. [CrossRef]

4. Kim, K.W.; Cho, K.S.; Jang, J. A polycrystalline silicon thin-film transistor with a thin amorphous buffer. IEEE Electron Device Lett. 1999, 20, 560-562. [CrossRef]

5. Lozac'h, M.; Nunomura, S.; Sai, H.; Matsubara, K. Passivation property of ultrathin SiOx:H/a-Si:H stack layers for solar cell applications. Sol. Energy Mater. Sol. Cells 2018, 185, 8-15. [CrossRef]

6. Kanneboina, V.; Madaka, R.; Agarwal, P. High open circuit voltage c-Si/a-Si:H heterojunction solar cells: Influence of hydrogen plasma treatment studied by spectroscopic ellipsometry. Sol. Energy Mater. Sol. Cells 2018, 166, 255-266. [CrossRef]

7. Lee, S.W.; Heo, D.C.; Kang, J.K.; Park, Y.B.; Rhee, S.W. Microcrystalline Silicon Film Deposition from $\mathrm{H}_{2}-\mathrm{He}_{\mathrm{SiH}}$ Using Remote Plasma Enhanced Chemical Vapor Deposition. J. Electrochem. Soc. 1998, 145, 2900-2904. [CrossRef]

8. Sakata, I.; Okazaki, S.; Yamanaka, M.; Hayashi, Y. Raman Scattering Studies on Hydrogenated Amorphous Silicon Prepared under High Deposition Rate Conditions. Jpn. J. Appl. Phys. 1985, 24, L428-L430. [CrossRef]

9. Morell, G.; Katiyar, R.S.; Weisz, S.Z.; Balberg, I. Characterization of the silicon network disorder in hydrogenated amorphous silicon carbide alloys with low carbon concentrations. J. Non-Cryst. Solids 1996, 194, 78-84. [CrossRef]

10. Park, J.; Iftiquar, S.M.; Kim, Y.K.; Park, S.M.; Lee, S.W.; Kim, J.D.; Yi, J. Spectroscopic Ellipsometry Analysis of Amorphous Silicon Thin Films for Si-Nanocrystals. J. Nanosci. Nanotechnol. 2012, 12, 3228-3232. [CrossRef]

11. Liao, N.M.; Li, W.; Liu, Z.; Jiang, Y.D.; Ma, N.; Li, Y.; Wu, Z.M.; Li, S.B. Effects of irradiation with electrons of different energies on the dark conductivity and the network of hydrogenated amorphous silicon films. Philos. Mag. Lett. 2008, 88, 871-877. [CrossRef]

12. Funde, A.M.; Bakr, N.A.; Kamble, D.K.; Hawaldar, R.R.; Amalnerkar, D.P.; Jadkar, S.R. Influence of hydrogen dilution on structural, electrical and optical properties of hydrogenated nanocrystalline silicon (nc-Si:H) thin films prepared by plasma enhanced chemical vapour deposition (PE-CVD). Sol. Energy Mater. Sol. Cells 2008, 92, 1217-1223. [CrossRef] 
13. Angermann, H.; Conrad, E.; Korte, L.; Rappich, J.; Schulze, T.F.; Schmidt, M. Passivation of textured substrates for a-Si:H/c-Si hetero-junction solar cells: Effect of wet-chemical smoothing and intrinsic a-Si:H interlayer. Mater. Sci. Eng. B 2009, 159, 219-223. [CrossRef]

14. Werner, F.; Veith, B.; Zielke, D.; Kuhnemund, L.; Tegenkamp, C.; Seibt, M.; Brendel, R.; Schmidt, J. Electronic and chemical properties of the c-Si $/ \mathrm{Al}_{2} \mathrm{O}_{3}$ interface. J. Appl. Phys. 2011, 109, 113701. [CrossRef]

15. Kim, S.K.; Lee, J.C.; Park, S.J.; Kim, Y.J.; Yoon, K.H. Effect of hydrogen dilution on intrinsic a-Si:H layer between emitter and Si wafer in silicon heterojunction solar cell. Sol. Energy Mater. Sol. Cells 2008, 92, 298-301. [CrossRef]

16. Sinton, R.A.; Cuevas, A. Contactless determination of current-voltage characteristics and minority-carrier lifetimes in semiconductors from quasi-steady-state photoconductance data. Appl. Phys. Lett. 1996, 69, 2510-2512. [CrossRef]

17. Park, J.; Jang, K.S.; Shin, D.G.; Shin, M.; Yi, J.S. Gate-induced drain leakage current characteristics of p-type polycrystalline silicon thin film transistors aged by off-state stress. Solid-State Electron. 2018, 148, $20-26$. [CrossRef]

18. Proano, R.E.; Misage, R.S.; Ast, D.G. Development and electrical properties of undoped polycrystalline silicon thin-film transistors. IEEE Trans. Electron Devices 1989, 36, 1915-1922. [CrossRef]

19. Levinson, J.; Shepherd, F.R.; Scanlon, P.J.; Westwood, W.D.; Este, G.; Rider, M. Conductivity behavior in polycrystalline semiconductor thin film transistors. J. Appl. Phys. 1982, 53, 1193. [CrossRef]

20. Kuo, Y. Plasma enhanced chemical vapor deposited silicon nitride as a gate dielectric film for amorphous silicon thin film transistors-A critical review. Vacuum 1998, 51, 741-745. [CrossRef]

21. Kim, J.; Sohn, K.; Jang, J. Temperature dependent leakage currents in polycrystalline silicon thin film transistors. IEEE Trans. Electron Devices 1990, 37, 1727-1734. [CrossRef]

(C) 2019 by the authors. Licensee MDPI, Basel, Switzerland. This article is an open access article distributed under the terms and conditions of the Creative Commons Attribution (CC BY) license (http:/ / creativecommons.org/licenses/by/4.0/). 